\title{
The Impact of a Hospital-Based Awareness Program on the Knowledge of Patients About Breast Cancer and Cancer Cervix
}

\author{
Azza Mohamed Elsayed Atwa ${ }^{1}$, Hanan Elzeblawy Hassan ${ }^{2} \&$ Safaa Ibrahim Ahmed ${ }^{1}$ \\ ${ }^{1}$ Obstetrics \& Gynecology Nursing, Faculty of Nursing, Sohag University, Egypt \\ ${ }^{2}$ Maternal \& Newborn Health Nursing, Faculty of Nursing, Beni-Suef University, Egypt \\ Correspondence: Hanan Elzeblawy Hassan, Faculty of Nursing, Beni-Suef University, Egypt. E-mail: \\ nona_nano_1712@yahoo.com \\ Received: November 20, 2018 \\ Accepted: January 2, 2019 \\ Online Published: January 8, 2019 \\ doi:10.20849/ijsn.v4i1.537 \\ URL: https://doi.org/10.20849/ijsn.v4i1.537
}

\begin{abstract}
Background: Breast cancer and cancer cervix contribute to high morbidity and mortality rates among women worldwide. Appropriate knowledge of both cancers can help in early detection and management. Aim: This study aimed to assess the effect of a hospital-based awareness program on the knowledge of patients attending some outpatient clinics in Sohag University Hospital regarding the 2 cancers. Subjects and Methods: The program was held in Sohag University Hospital on 150 female patients during the period between August and October 2018. The knowledge of the patients about the risk factors, symptoms, screening, and management of both cancers was first assessed using an interview questionnaire. Then, the awareness program included 4 sessions and every session discussed only 1 aspect of knowledge regarding both cancers. Later, patients were assessed again using the same questionnaire and the improvement was determined. Results: The mean age of the participating patients was $29.6 \pm 6.7$ years, $74.7 \%$ could read and write, and $85.3 \%$ were married. Only education was associated with better knowledge about breast cancer $(\mathrm{p}=0.002)$ and cancer cervix $(\mathrm{p}=0.007)$. Thanks to the program, the percent of patients with optimal knowledge of breast cancer improved from $14.7 \%$ to $50 \%$ ( $\mathrm{p}<$ 0.001). This percent distributed as follows; risk factors $10 \%$ to $50 \%$ ( $\mathrm{p}<0.001$ ), manifestations $20 \%$ to $60 \%$ ( $\mathrm{p}<$ 0.001 ), screening $4 \%$ to $7 \%(\mathrm{p}<0.001)$, and management $24.8 \%$ to $63 \%(\mathrm{p}<0.001)$. Regarding cancer cervix, the improvement was as follows; total knowledge $13.3 \%$ to $46.2 \%$ ( $<<0.001$ ), risk factors $8 \%$ to $50 \%$ ( $p<$ 0.001 ), manifestations $12.2 \%$ to $50 \%$ ( $p<0.001$ ), screening $15 \%$ to $40 \%$ ( $p<0.001$ ), and management $18.2 \%$ to $44.8 \%$ ( $\mathrm{p}<0.001$ ). Conclusion and Recommendations: Patients had suboptimal knowledge about breast cancer and cancer cervix. However, the program achieved remarkable successes in improving the knowledge of patients. Future programs on a wider scale and different populations should be considered.
\end{abstract}

Keywords: breast cancer, cancer cervix, knowledge, awareness program

\section{Introduction}

Breast cancer poses the highest prevalence of all cancers among women and leads to the highest cancer-associated mortalities. ${ }^{[1-3]}$ In the USA more than 40.5 thousand deaths attributed to breast cancer were recorded during 2017. ${ }^{[4]}$ Nationally, breast cancer represented more than a third of all cancers affecting women in 2011 with high incidence and prevalence rates. ${ }^{[5,6]}$ In Egypt, recently WHO in 2014 had announced that BC is the most common cancer among Egyptian women with the mean age at diagnosis is ten years lower than in the United States and Europe. ${ }^{[7]}$ It represents for $32.0 \%$ of cancer cases among Egyptian women with high dominated frequency in Upper, Middle, and Lower Egypt (38.7\%, 33.8\%, and 26.8\%, respectively). However, a study in 2014 reported that Breast cancer was diagnosed in 19105 Egyptian women. ${ }^{[8]}$

Breast cancer is considered the most horrible cancer for women. ${ }^{[9,10]}$ It is a heterogeneous disease with unknown causes. Yet it has multidimensional risk factors specifically; genetic predisposition, family history, personal history, female sex and increasing age. In addition to, hormonal related risk factors. ${ }^{[11-13]}$ However, what is noisy about diagnosis of breast cancer is that it has almost no symptoms during its early stages which makes its early detection challenging. This is although early detection of the cancer can provide higher cure and survival rates. Meanwhile, screening for breast cancer is important for its detection in early stages. ${ }^{[14,15]}$ WHO delineated that $30 \%-50 \%$ of cancers can be inhibited through avoidance of risk factors and screening measures. ${ }^{[11]}$ This screening can be done at home or at special clinics via breast self-examination, clinical breast examination, 
and/or mammography. ${ }^{[8,9]}$

Breast self-examination (BSE) is the most healthful monthly performed protective behavior that is recommended for all women at any age starting from 20 years along their life span. It is considered to be the easiest, noninvasive, and costless screening procedure. ${ }^{[16-18]}$ Breast self-examination is recommended by World Health Organization as an individual measure for raising women's awareness about BC risks and its early detection. However, overutilization of BSE and improper performance can lead to misleading or false results. Thus, the American Cancer Society screening guidelines for BC in 2015 further suggested that women should be informed about the possible advantages, disadvantages of BSE and the value of immediate reporting of any discovered breast changes to health professionals. ${ }^{[11,16]}$

On the other hand, cancer cervix, however less common than breast cancer, can be life-threating as well. ${ }^{[19,20]}$ The morbidity rates of cancer cervix differ widely among studies due to many social, ethnic, and behavioral reasons. ${ }^{[1,2]}$ In Egypt, cancer cervix is 20 times less common than breast cancer and its mortality rates are inconsistence. ${ }^{[6]}$

Like breast cancer, early diagnosis of cancer cervix is crucial for its treatment and could improve the cure and survival rates. ${ }^{[7]}$ The widely-known Papanicolaou test (Pap smear test) is heavily used to screen for the cancer. This test carries many pros such as the low-cost, the effectiveness, and the high sensitivity. ${ }^{[20-24]}$

Previous literature spoke about the pivotal role of nurses; directly by participation in the screening programs and indirectly by raising the awareness of women about the necessity of screening for cancers. ${ }^{[25]}$ Meanwhile, the investigators in this study explored the impact of a hospital-based awareness program given by nurses on the knowledge of patients about breast cancer and cancer cervix.

\subsection{Significance of the Study}

Breast cancer and cancer cervix are of public health concern and despite the great benefits with low cost of screening procedures (BSE, CBE, mammogram, and Papanicolaou test), their utilization remains very low due to women's lack of awareness which can further influence their screening behavior. ${ }^{[26-29]}$ However, little is known about the knowledge of patients about the risk factors, symptoms, screening, and management of both cancers and whether awareness programs could be effective in improving their knowledge or not. We believe that knowledgeable people can spread the awareness among their relatives and could benefit from the awareness in early detection of breast cancer and cancer cervix that might affect them.

\subsection{Aim of the Study}

The aim of this study was to evaluate the effect of a hospital-based program on the knowledge of patients attending the outpatient clinics of Sohag University Hospital about risk factors, manifestations, screening, and management of breast cancer and cancer cervix.

\subsection{Research Hypothesis}

We hypothesized that the program would improve the knowledge of patients about breast cancer and cancer cervix.

\section{Methods}

\subsection{Study Design}

A quasi-experimental design was adopted.

\subsection{Setting and Time Frame}

The awareness program was held in Sohag University Hospital over 4 sessions; 90 minutes each and continued for 2 days. However, the inclusion of the patients was continuous, so the same program using the same educators and materials was repeated over 2 months between August and October 2018. The assessment of the patients' knowledge was done before and after the program.

\subsection{Sampling}

The sample size was calculated using the program; Epi-Info version 7 Stat Calc, [Center for Disease Control (CDC), World Health Organization (WHO)], an improvement of the optimal knowledge with $25 \%$, a confidence level of $95 \%$, and a margin of error of $5 \%$.

A total of 200 patients attending the outpatient clinics of Gynecology and Obstetrics in Sohag University Hospital were chosen randomly over 1 week in a consecutive manner. Of the 200 patients, 150 accepted to participate and attended the awareness giving us a response rate of $75 \%$. 


\subsection{Fieldwork and Data Collection}

The authors prepared an Arabic questionnaire for the sake of data collection. The questionnaire comprised of 3 sections. Section I included questions about the demographic characters of the patients; name, age, residence, education. Marital status, family history of breast cancer or cancer cervix, and history of attending awareness programs about the same topics.

Section II evaluated the knowledge of patients about breast cancer using 16 statements and patients were asked to show to what extent they agreed or disagreed with these statement on a Likert scale from 1 to 5 in which 1 referred to strongly disagree and 5 to strongly agree. Reverse questions had inverse scores. The 16 statements were equally divided on 4 subdivisions; risk factors, manifestations, screening, and management of breast cancer. The score of each division was 20 and the total score was the average of the 4 subdivisions. Patients with scores higher than $60 \%$ of the division score or the total score were considered of optimal knowledge regarding this division and/or the total knowledge.

Alike, section III included the same number of questions divided on the same 4 aspects but to assess the knowledge about cancer cervix. The same scoring system was applied.

For more details, the risk factors division of breast cancer evaluated the knowledge of patients about the effect of diet, family history, different traits of metabolic syndrome, and gynecological disorders on the occurrence of breast cancer. The manifestations division included 2 statements about the local symptoms and 2 statements about the general symptoms of breast cancer. The screening division included statements about the age of first screening, methods of screening ( 2 statements), and spacing between screening. The management division evaluated the knowledge of patients about 4 procedures of treatment; chemotherapy, radiotherapy, surgery, and hormonal therapy.

Regarding cancer cervix, the division of risk factors evaluated the knowledge of patients about the effect of age, sexually transmitted infections, contraception, and obesity on the development of cancer cervix. The division of manifestations was like that of breast cancer (2 local and 2 general symptoms). The screening division included statements about the age of first screening, methods, times, and accuracy of screening. The management division assessed knowledge of patients about chemotherapy, radiotherapy, surgery, and psychological rehabilitation.

The investigators interviewed the patients twice, 1 time before the start of the program and 1 time immediately after the last session.

\subsection{Pilot Study}

Before putting the questionnaire in practice a pilot study on 10 patients were conducted to test the validity and reliability of the questionnaire.

\subsection{Validity \& Reliability}

The Cronbach's alpha for reliability was 0.77 , while the content validity was assessed by a professor of public health and 3 professors of maternity, obstetrics \& gynecologic nursing.

\subsection{Program Sessions}

The awareness program, designed by the investigators, included 4 sessions; 90 minutes each, on 2 consecutive days. Session 1 included information about the familial, nutritional, lifestyles (e.g. inactivity, poor dietary habits, smoking, and alcohol intake) and medical risk factors associated with both cancers. The second session discussed the possible manifestations associated with the cancers. Session 3 discussed the pivotal role of screening in detecting early cases, age of screening, times of screening, and its accuracy. The last session covered cancer's preventive measures and discussed the possible treatment procedures based on the type and grade of cancer (surgical, chemotherapy, radiotherapy).

We adopted problem-solving approach in the awareness sessions. This approach allowed patients to participate and discuss their concerns. During the awareness sessions, presentations, short films, and group discussion were held. At the end of each session, the investigators summarized the important points of this session and the participants were encouraged to ask and show their personal experience. Booklets, brochures and leaflets, supported by illustrated figures, were distributed as take-home notes. Patients who missed 1 or more sessions during the program were given wrap-ups of what they have missed. 
Table 1. Overview of the elements in the program about women's' knowledge regarding breast cancer and cancer cervix (duration 3 months)

\begin{tabular}{|c|c|c|c|c|c|c|}
\hline Phases & & No. & Elements & $\begin{array}{l}\text { Objectives } \\
\end{array}$ & Method & \\
\hline 竭 & & Oper & ning Ceremony & $\begin{array}{l}\text { - Welcome and Presentation program objectives. } \\
\text { - Enumerate the participants' expectations. } \\
\text { - Distribution of pre-test. }\end{array}$ & $\begin{array}{l}\text { - Discussion. } \\
\text { - Distribution } \\
\text { booklet }\end{array}$ & of \\
\hline \multirow{4}{*}{ 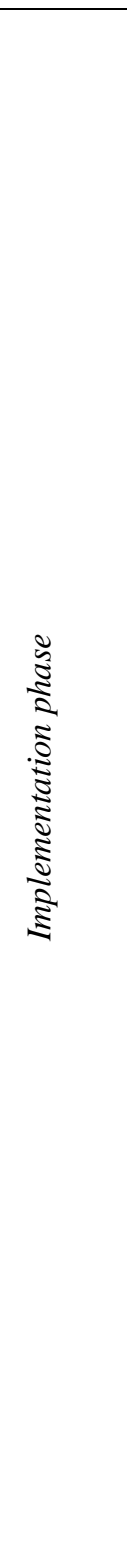 } & $\frac{\vec{\sigma}}{\vec{\sigma}^{2}}$ & 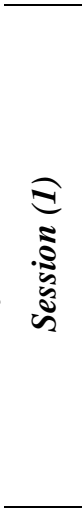 & $\begin{array}{l}\text { knowledge } \\
\text { regarding the } \\
\text { factors } \\
\text { associated with } \\
\text { breast and } \\
\text { cervical cancer }\end{array}$ & $\begin{array}{l}\text { - Define breast cancer } \\
\text { - List factors risk factors associated with breast cancer } \\
\text { a. Mention familial and genetic risk factors } \\
\text { b. Mention nutritional risk factors } \\
\text { c. Mention life styles risk factors as inactivity, poor } \\
\text { dietary habits, smoking, and alcohol intake. } \\
\text { d. Mention medical and hormonal risk factors } \\
\text { - Define cervical cancer } \\
\text { - List risk factors associated with cervical cancer } \\
\text { a. Mention familial risk factors } \\
\text { b. Mention nutritional \& lifestyles risk factors } \\
\text { c. Mention medical risk factors }\end{array}$ & - Power point & \\
\hline & & 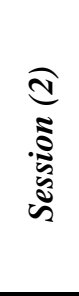 & $\begin{array}{l}\text { knowledge } \\
\text { regarding } \\
\text { manifestations } \\
\text { associated with } \\
\text { breast and } \\
\text { cervical cancer }\end{array}$ & $\begin{array}{l}\text { - Describe manifestations associated with breast cancer } \\
\text { a. Mention general manifestations } \\
\text { b. Mention local manifestations } \\
\text { - Describe manifestations associated with cervical } \\
\text { cancer } \\
\text { a. Mention general manifestations } \\
\text { b. Mention local manifestations }\end{array}$ & $\begin{array}{l}\text { - Power point } \\
\text { - Video }\end{array}$ & \\
\hline & \multirow[b]{2}{*}{$\begin{array}{l}\text { हैं } \\
\text { हैं }\end{array}$} & 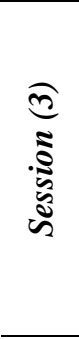 & $\begin{array}{l}\text { Knowledge } \\
\text { regarding } \\
\text { screening } \\
\text { measures for } \\
\text { breast and } \\
\text { cervical cancer }\end{array}$ & $\begin{array}{l}\text { - Mention the screening measures for breast cancer } \\
\text { a. Laboratory tests } \\
\text { b. Breast self-examination } \\
\text { c. Clinical breast examination } \\
\text { d. Mammogram } \\
\text { Mention the screening measures for cervical cancer } \\
\text { a. Laboratory tests } \\
\text { b. Pap smear }\end{array}$ & $\begin{array}{l}\text { - Power point } \\
\text { - Video } \\
\text { - Demonstration }\end{array}$ & \\
\hline & & 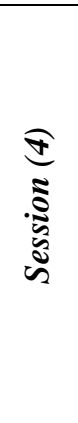 & $\begin{array}{l}\text { Knowledge } \\
\text { regarding } \\
\text { possible } \\
\text { treatment } \\
\text { procedures }\end{array}$ & $\begin{array}{l}\text { - Mention the preventive measures and treatment } \\
\text { procedures for breast cancer } \\
\text { a. Surgical } \\
\text { b. Chemotherapy } \\
\text { c. Radiotherapy } \\
\text { - Mention the preventive measures and treatment } \\
\text { procedures for cervical cancer } \\
\text { a. Surgical } \\
\text { b. Chemotherapy } \\
\text { c. Radiotherapy }\end{array}$ & $\begin{array}{l}\text { - Power point } \\
\text { - Video }\end{array}$ & \\
\hline 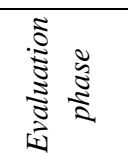 & & & Closing & - Distribution of Post-test. & $\begin{array}{l}\text { - Thanks } \\
\text { participants. }\end{array}$ & to \\
\hline
\end{tabular}

\subsection{Ethical Considerations}

The study was conducted in full accordance with the guidelines for the Declaration of Helsinki, and data for each participant were collected only after obtaining informed consent. The research ethics committee of Sohag University gave its approval to the protocol.

\subsection{Data Analysis}

Data were analyzed using the software, Statistical Package for Social Science (SPSS Inc. Released 2009, PASW 
Statistics for Windows, version 18.0: SPSS Inc., Chicago, Illinois, USA). Frequency distribution and descriptive statistics were calculated. Chi-square and t-test were done whenever needed. $\mathrm{P}$ values of less than 0.05 were considered significant. The graphical presentation included 3-D Clustered Column and Pie chart diagram.

\section{Results}

A total of 150 patients attending different outpatient clinics in Sohag University Hospital participated in this study. The age of the patients was $29.6 \pm 6.7$ years. Most of the patients $70.7 \%$ were residing in rural areas, $74.7 \%$ were literate, and $85.3 \%$ were married. Only $3.3 \%$ had a positive history of any of the 2 cancers and $4 \%$ reported attending previous awareness programs (Table 2).

When the 22 patients with baseline optimal knowledge about breast cancer were compared to their 128 counterparts with suboptimal baseline knowledge, only education associated with better knowledge $(p=0.002)$ (Table 3).

The same finding was detected also among the 20 patients with baseline optimal knowledge about cancer cervix in comparison to the 130 patients with suboptimal baseline knowledge $(\mathrm{p}=0.007)$ (Table 4).

After the program, the percent of patients with optimal knowledge of breast cancer improved from $14.7 \%$ to $50 \%$ $(\mathrm{p}<0.001)$. This percent distributed as follows; risk factors $10 \%$ to $50 \%(\mathrm{p}<0.001)$, manifestations $20 \%$ to $60 \%$ ( $\mathrm{p}<0.001$ ), screening $4 \%$ to $27 \%$ ( $\mathrm{p}<0.001)$, and management $24.8 \%$ to $63 \%(\mathrm{p}<0.001)$ (Figure 1 ).

Regarding cancer cervix, the improvement was as follows; total knowledge $13.3 \%$ to $46.2 \%$ ( $<0.001$ ), risk factors $8 \%$ to $50 \%$ ( $<<0.001$ ), manifestations $12.2 \%$ to $50 \%$ ( $\mathrm{p}<0.001$ ), screening $15 \%$ to $40 \%$ ( $\mathrm{p}<0.001$ ), and management $18.2 \%$ to $44.8 \%$ ( $\mathrm{p}<0.001$ ) (Figure 2 ).

Table 2. Demographic characteristics of the patients, Sohag University Hospital, 2018

\begin{tabular}{llc}
\hline \multicolumn{2}{l}{ Demographic characteristics } & N $=\mathbf{1 5 0}(\boldsymbol{\%})$ \\
\hline \multicolumn{2}{l}{ Age (Mean \pm SD) years } & $29.6 \pm 6.7$ \\
Residence & Urban & $44(29.3)$ \\
\multirow{2}{*}{ Education } & Rural & $106(70.7)$ \\
& Literate & $112(74.7)$ \\
Family history & Illiterate & $38(25.3)$ \\
& Positive & $5(3.3)$ \\
Marriage status & Negative & $145(96.7)$ \\
\multirow{2}{*}{ Previous awareness } & Married & $128(85.3)$ \\
& Not married & $22(14.7)$ \\
& Yes & $6(4.0)$ \\
\end{tabular}

Table 3. Relation between the demographic characteristics of the patients and their baseline knowledge about breast cancer, Sohag University Hospital, 2018

\begin{tabular}{|c|c|c|c|c|}
\hline \multicolumn{2}{|c|}{ Demographic characteristics } & Optimal $n=22(\%)$ & Suboptimal $n=128(\%)$ & P value \\
\hline \multicolumn{2}{|c|}{ Age $($ Mean \pm SD) years } & $27.1 \pm 5.7$ & $30.6 \pm 7.7$ & 0.443 \\
\hline \multirow{2}{*}{ Residence } & Urban & $6(27.2)$ & $38(29.7)$ & \multirow{2}{*}{0.866} \\
\hline & Rural & $16(72.8)$ & $90(70.3)$ & \\
\hline \multirow{2}{*}{ Education } & Literate & $20(90.1)$ & $92(71.9)$ & \multirow{2}{*}{$0.002 *$} \\
\hline & Illiterate & $2(9.9)$ & $36(18.1)$ & \\
\hline \multirow{2}{*}{ Family history } & Positive & $1(4.5)$ & $4(3.1)$ & \multirow{2}{*}{0.888} \\
\hline & Negative & $21(95.5)$ & $124(96.9)$ & \\
\hline \multirow{2}{*}{ Marriage status } & Married & $18(81.8)$ & $110(85.9)$ & \multirow{2}{*}{0.731} \\
\hline & Not married & $4(18.2)$ & $18(14.1)$ & \\
\hline \multirow{2}{*}{ Previous awareness } & Yes & $1(4.5)$ & $5(3.3)$ & \multirow{2}{*}{0.870} \\
\hline & No & $21(95.5)$ & $123(96.7)$ & \\
\hline
\end{tabular}

*p value is considered significant 
Table 4. Relation between the demographic characteristics of the patients and their baseline knowledge about cancer cervix, Sohag University Hospital, 2018

\begin{tabular}{|c|c|c|c|c|}
\hline \multicolumn{2}{|c|}{ Demographic characteristics } & Optimal n = 20 (\%) & Suboptimal $\mathrm{n}=130(\%)$ & Pvalue \\
\hline \multicolumn{2}{|c|}{ Age $($ Mean \pm SD) years } & $27.8 \pm 8.6$ & $30.8 \pm 7.7$ & 0.352 \\
\hline \multirow{2}{*}{ Residence } & Urban & $5(25.0)$ & $38(29.2)$ & \multirow{2}{*}{0.548} \\
\hline & Rural & $15(75.0)$ & $92(70.8)$ & \\
\hline \multirow{2}{*}{ Education } & Literate & $18(90.0)$ & $94(72.3)$ & \multirow{2}{*}{$0.007 *$} \\
\hline & Illiterate & $2(10.0)$ & $36(17.7)$ & \\
\hline \multirow{2}{*}{ Family history } & Positive & $1(5.0)$ & $4(3.1)$ & \multirow{2}{*}{0.741} \\
\hline & Negative & $19(95.0)$ & $126(96.9)$ & \\
\hline \multirow{2}{*}{ Marriage status } & Married & $18(90.0)$ & $110(84.6)$ & \multirow{2}{*}{0.546} \\
\hline & Single & $2(10.0)$ & $20(15.4)$ & \\
\hline \multirow{2}{*}{ Previous awareness } & Yes & $1(5.0)$ & $5(3.8)$ & \multirow{2}{*}{0.611} \\
\hline & No & $19(95.0)$ & $125(96.2)$ & \\
\hline
\end{tabular}

*p value is considered significant

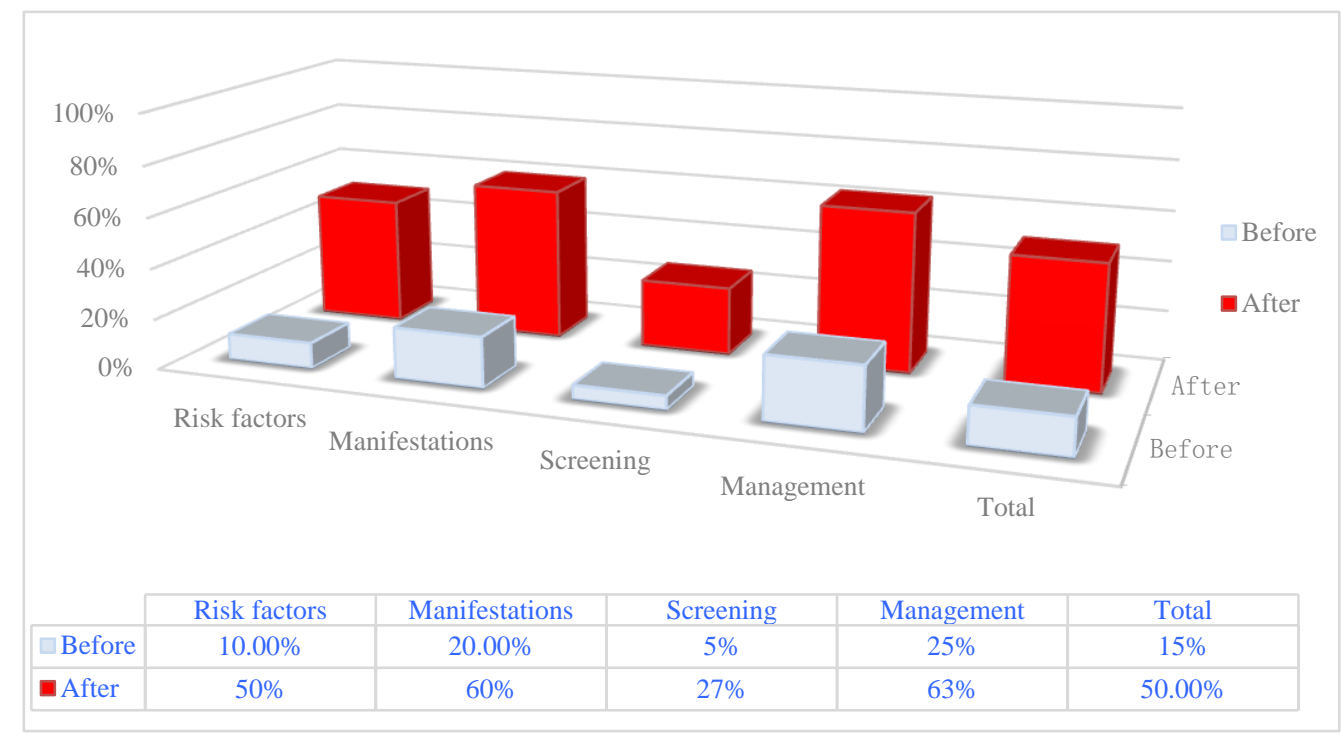

Figure 1. Improvement of knowledge of the patients about breast cancer after the program, Sohag University Hospital, 2018 ( $<<0.001$ each)

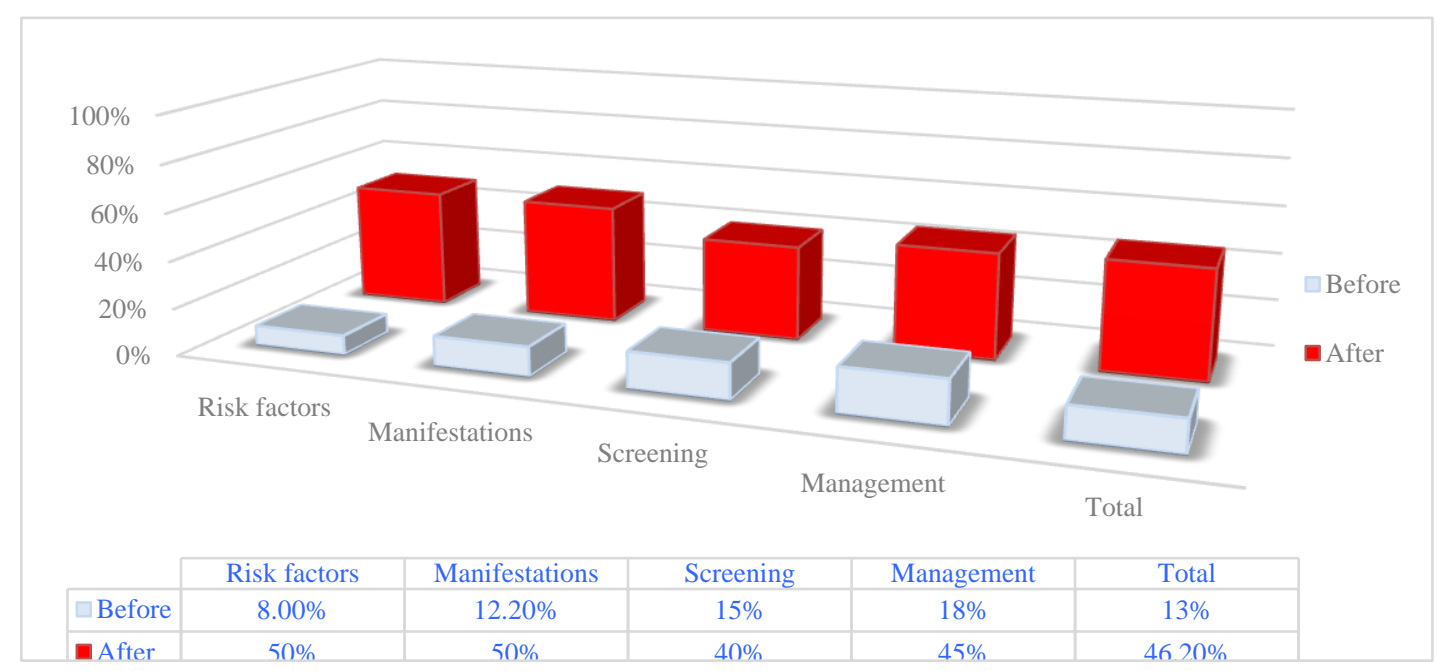

Figure 2. Improvement of knowledge of the patients about cancer cervix after the program, Sohag University Hospital, 2018 ( $\mathrm{p}<0.001$ each) 


\section{Discussion}

Breast/Cervical cancer is considered as a public health emergency issue and one of the chief causes of increased mortality/disability among women despite its preventable nature through early detection. Thus, Healthy People 2020 highlighted a chief delineated goal to decrease the new diagnosed cases. However, this goal is impossible to be achieved with the wave of the lack of women's knowledge and awareness about nature, risk factors, manifestations, treatment, and understanding of their preventive measures and detection screening measures technique. ${ }^{[30-33]}$

Evidently, in 2015, Egypt Demographic Health Survey (EDHS) reported that only 11.0\% of, aged 15-59 years, women were aware of how to conduct BSE to recognize signs of BC and only $6 \%$ of them were actually had performed BSE in the previous year. ${ }^{[33]}$ Therefore, the current study was conducted with the aim of evaluate the effect of a hospital-based program on the knowledge of patients attending the outpatient clinics of Sohag University Hospital about risk factors, manifestations, screening, and management of breast cancer and cancer cervix.

The morbidities and mortalities attributed to different cancers constitute a huge burden on underdeveloped countries. However, screening for cancers can help in early detection and appropriate treatment. The awareness of people about cancer and the importance of screening will increase their chance to screen for the disease regularly. ${ }^{[34]}$ The current study evaluated the knowledge of patients about 2 important cancers; breast cancer and cancer cervix and assessed the impact of a hospital-based awareness program on their knowledge about both cancers.

The baseline results of this study showed that our patients had suboptimal knowledge about all aspects of breast cancer. Similar limitations were recorded in studies from Brazil ${ }^{[35,36]}$, Ethiopia ${ }^{[37]}$, Turkey ${ }^{[38,39]}$, Singapore ${ }^{[40]}$, Pakistan ${ }^{[41]}$, the $\mathrm{USA}^{[42]}$, and Egypt ${ }^{[43]}$ It should be noted that the cited studies were conducted on different population samples using different study designs and data collecting methods. However, the common finding was the suboptimal knowledge of the surveyed people.

Our results showed that education associated with better knowledge scores. This finding seems reasonable because educated people have more sources of knowledge. Yet, we did not find an association between the positive family history and knowledge which contradicted previous findings. ${ }^{[11,12]}$ Nevertheless, only 5 patients reported a positive family history of breast cancer or cancer cervix. This low number is not enough for the statistical analyses to show significant differences.

Alike, we recorded low baseline knowledge among our patients regarding cancer cervix. Our results agreed with previous findings on populations from Singapore ${ }^{[40]}$, India ${ }^{[44,45]}$, Nepal and Sri Lanka ${ }^{[46]}$, and the USA ${ }^{[42,47]}$ which found low knowledge about cancer cervix. Like the studies of breast cancer, these studies investigated different populations using different research methods and data collecting tools. Again, educated patients in our study showed better knowledge about cancer cervix compared to their illiterate counterparts.

Moving to the crucial part of this study, our program led to remarkable improvements in the knowledge of patients about breast cancer and cancer cervix. These improvements included all aspects of knowledge; risk factors, manifestations, screening, and management.

Many interventional studies targeted improving the knowledge of women about breast cancer and cancer cervix. These programs were performed on women from Iran ${ }^{[48]}$, Saudi Arabia ${ }^{[49]}$, Turkey ${ }^{[50]}$, Malaysia ${ }^{[51]}$ and the USA ${ }^{[52]}$ and recorded some achievements. Many differences regarding the used materials, assessment tools, and duration of the program were noted, however, most studies showed various improvements. This highlights the value of the educational intervention on improving knowledge level.

The positive effect of our hospital-based awareness program could be attributed to many factors. First, the program was divided on 4 sessions and each session discussed only 1 aspect of knowledge about both cancers. This offered patients a chance to fully understand all aspects of knowledge. We also allowed patients who missed 1 or 2 sessions to complete the program and attend the remaining sessions after giving them the summary of the sessions they missed.

Further, our awareness program was designed to be suitable for patients with low educational levels through using simple definitions, direct phrases, and illustrating figures. Moreover, the investigators encouraged the participants to ask, discuss their concerns, and narrate their personal experiences.

Another advantage was conducting the program in Sohag University Hospital where patients were seeking healthcare. This encouraged patients to complete the program and created an appropriate environment for the success of the program. 


\section{Conclusion and Recommendations}

In conclusion, the knowledge of the patients about breast cancer and cancer cervix was unsatisfactory, especially, regarding the screening division. However, the hospital-based awareness program achieved remarkable successes in improving the knowledge.

\section{Recommendations}

Further awareness programs should be conducted regularly and on a wider scale for all women's in all different ages in Egypt.

\section{References}

[1]. United Nations. (2017). World Cancer Day. Retrieved 4 February, 2017, from http:www.un.org/en/events/cancerday

[2]. World Health Organization (WHO). (2018). World Cancer Day. Retrieved from http://www.who.int/cancer/world-cancer-day/2018/en/

[3]. Qalawa, S.H., Eldeeb, A., \& Hassan, H. (2015). Young Adult Women's intention regarding breast and cervical cancer screening in Beni-Suef. Scientific Research Journal, 3(3), 11-24.

[4]. American Cancer Society, Breast Cancer Facts \& Figures 2017-2018.

[5]. Mohammed, F., Shahin, M., Youness, E., \& Hassan, H. (2018). Survivorship in Women Undergoing Gynecological and Breast Cancer Treatment in Upper Egypt: The Impact of Quality of Life Improvement Educational Program. American Research Journal of Gynaecology, 2(1), 1-28. https://doi.org/10.21694/2577-5928.18001

[6]. Ibrahim, A., Khaled, H., Mikhail, N., Baraka, H., \& Kamel, H. (2014). Cancer Incidence in Egypt: Results of the National Population-Based Cancer Registry Program. Journal of Cancer Epidemiology, (2014), 1-14. https://doi.org/10.1155/2014/437971

[7]. World Health Organization. (2014). Breast cancer: prevention and control. Retrieved 23 May, 2014, from http://www.who.int/cancer/detection/breastcancer/en/

[8]. Nady, F., Said, M., Youness, E., \& Hassan, H. (2017). Impact of Tailored Educational Program of Quality of Life Improvement on Women Undergoing Breast Cancer Treatment at El-Minia Region, Egypt. American Research Journal of Gynaecology, 1(1), 1-17. https://doi.org/10.21694/2577-5928.17001

[9]. Singh, M., \& Jangra, B. (2013). Association between body mass index and risk of breast cancer among females of north India. South Asian Journal of Cancer, 2(3), 121-125. https://doi.org/10.4103/2278-330X.114108

[10]. Obaji, N.C., Elom, H.A., Agwu, U.M., Nwigwe, C.G., Ezeonu, P.O., \& Umeora, O.U. (2013). Awareness and Practice of Breast Self-Examination among Maket Women in Abakaiki, South East Nigeria. Annals of Medical and Health Sciences Research, 3(1), 7-12. https://doi.org/10.4103/2141-9248.109457

[11]. World Health Organization. (WHO). (2018). World Cancer Day. Retrieved 25 March, 2018, from http://www.who.int/cancer/world-cancer-day/2018/en/

[12]. Anothaisintawee, T.H., Wiratkapun, C.H., Lerdsitthichai, P., Kasamesup, V., Wongwaisayawan, S., Srinakarin, J., et al. (2013). Risk Factors of Breast Cancer: A Systematic Review and Meta-Analysis. Asia-Pacific Journal of Public Health, 25(5), 1-20. https://doi.org/10.1177/1010539513488795

[13]. Michael, B. (2017). Breast Cancer Update. Windsong Radiology Group. Retrieved from http://blog.chsbuffalo.org/wp-content/uploads/2016/12/01-17-2017-Dr.-Peyser-Breast-Cancer-Update.pdf

[14]. Aydin, A.I., Kumcagiz, H., Altinel, B., \& Caloglu, A. (2014). Turkish female academician self-esteem and health beliefs for breast cancer screening. Asian Pac $J$ Cancer Prev, 15, 155-160. https://doi.org/10.7314/APJCP.2014.15.1.155

[15].Ersin, F., \& Bahar, Z. (2012). Effects of health promotion models on breast cancer early detection behaviors: a literature review. Dokuz Eylul Univers Nurs School J., 5, 28-38.

[16]. Oeffinger, K.C., Fontham, E.T., Etzioni, R., Herzig, A., Michaelson, J.S., Shih, Y.C., et al. (2015). Breast cancer screening for women at average risk: 2015 guideline update from the American Cancer Society. JAMA, 314(15), 1599-1614. https://doi.org/10.1001/jama.2015.12783

[17]. Shalini, Varghese, D., \& Nayak, M. (2011). Awareness and impact of education on breast self- examination among college going girls. Indian J Palliat Care, 17(2), 150-154. https://doi.org/10.4103/0973-1075.84538

[18]. Harris, J.R., Lippman, E., Morrow, M., \& Kent, O.C. (2014). Diseases of the breast: Physical Exam of the Breast (5th ed.). Philadelphia: Wolters Kluwer Health Adis (ESP). 
[19].Nady, F., El-Sherbiny, M., Youness, E., \& Hassan, H. (2018). Effectiveness of Quality of Life Planned Teaching Program on Women Undergoing Gynecologic Cancer Treatment. American Research Journal of Oncology, 1(1), 1-17.

[20]. Hassan, H., Bayoumi, M., \& Atwa, A. (2016). Emotional Distress Associated with Gynecologic and Breast Cancer in Beni-Suef City. International Journal of Science and Research, 5(2), 1118-1129.

[21]. Said, S., Hassan, H., \& Sarhan, A. (2018). Effect of an Educational Intervention on Women's Knowledge and Attitude Regarding Cervical Cancer. American Journal of Nursing Research, 6(2), 59-66. https://doi.org/10.12691/ajnr-6-2-4

[22]. Ozdemir, O., \& Bilgili, N. (2010). Knowledge and practices of nurses working in an education hospital on early diagnosis of breast and cervix cancers. TAF Prev Med Bulletin, 9, 605-612. https://doi.org/10.5455/pmb.20100427030359

[23]. Hassan, H., \& Atwa, A. (2017). Occupational Stress, Job Satisfaction and Cervical Screening Intention of Maternity Oncology Nurses. Medical Science \& Healthcare Practice, 1(1), 48-59. https://doi.org/10.22158/mshp.v1n1p48

[24]. Karadag, G., Gungormus, Z., Surucu, R., Savas, E., \& Bicer, F. (2014). Awareness and practices regarding breast and cervical cancer among Turkish women in Gazientep. Asian Pac J Cancer Prev, 15, 1093-1098. https://doi.org/10.7314/APJCP.2014.15.3.1093

[25]. Kanbur, A., \& Capik, C. (2011). Cervical cancer prevention, early diagnosis-screening methods and midwives/nurses role. Hacettepe University Health Science Faculty Nurs J, 18, 61-72.

[26]. Russell, K.M., Champion, V.L., Monahan, P.O., Millon-Underwood, S., Zhao, Q., Spacey, N., et al. (2010). Randomized trial of a lay health advisor and computer intervention to increase mammography screening in African American women. Cancer Epidemiol Biomarkers Prev., 19, 201-210. https://doi.org/10.1158/1055-9965.EPI-09-0569

[27]. Lin, Z.C., \& Effken, J.A. (2010). Effects of a tailored web-based educational intervention on women's perceptions of and intentions to obtain mammography. J Clin Nurs., 19, 1261-1269. https://doi.org/10.1111/j.1365-2702.2009.03180.x

[28]. Kim, J., Menon, U., Wang, E., \& Szalacha, L. (2010). Assess the effects of culturally relevant intervention on breast cancer knowledge, beliefs, and mammography use among Korean American Women. J Immigr Minor Health, 12, 586-597. https://doi.org/10.1007/s10903-009-9246-7

[29]. Oyekale, S., \& Oyekale, O. (2010). Application of health belief model for promoting behaviour change among Nigerian single youth. Afr J Reprod Health, 14(2), 63-75.

[30]. Arevian, M., Noureddine, S., \& Abboud, S. (2011). Beliefs related to breast cancer and breast cancer screening among Lebanese Armenian Women. Health Care Women Int., 32(11), 972-89. https://doi.org/10.1080/07399332.2011.580405

[31]. Mahfouzm, A.A., Hassanein, M.H., Nahar, S., Farheen, A., Gaballah, II., Mohamed, A., Rabie, F.M., \& Aftab, R. (2013). Breast cancer knowledge and related behaviors among women in Abha city, Southwestern Saudi Arabia. J Cancer Educ., 28(3), 516-520. https://doi.org/10.1007/s13187-013-0495-8

[32]. Othman, A., Ahram, M., Al-Tarawneh, R., \& Shahrouri, M. (2015). Knowledge, Attitudes and Practices of Breast Cancer Screening Among Women in Jordan. Health Care Women Int., 36(5), 578-592. https://doi.org/10.1080/07399332.2014.926900

[33]. Ministry of Health and Population/Egypt, El-Zanaty and Associates/Egypt, and ICF International. (2015). Egypt Health Issues Survey 2015. Cairo, Egypt: Ministry of Health and Population/Egypt and ICF International. Retrieved 26 March, 2018, from https://dhsprogram.com/pubs/pdf/FR313/FR313.pdf

[34]. Markovic, M., Kesic, V., Topic, L., \& Matejic, B. (2005). Barriers to cervical cancer screening: a qualitative study with women in Serbia. Soc Sci Med., 61, 2528-2535. https://doi.org/10.1016/j.socscimed.2005.05.001

[35]. Prolla, C., da Silva, P., Netto, C., Goldim, J., \& Ashton-Prolla, P. (2015). Knowledge about breast cancer and hereditary breast cancer among nurses in a public hospital. Rev Lat Am Enfermagem, 23(1), 90-97. https://doi.org/10.1590/0104-1169.0185.2529

[36]. Batiston, A., Tamaki, E., Souza, L., \& Santos, M. (2011). Conhecimento e prática sobre os fatores de risco para o câncer de mama entre mulheres de 40 a 69 anos. Rev. Bras. Saúde Mater. Infant, 11(2), 163-171. https://doi.org/10.1590/S1519-38292011000200007 
[37]. Lemlem, S., Sinishaw, W., Hailu, M., Abebe, M., \& Aregay, A. (2013). Assessment of Knowledge of Breast Cancer and Screening Methods among Nurses in University Hospitals in Addis Ababa. Ethiopia, 2011.ISRN Oncol. https://doi.org/10.1155/2013/470981

[38]. Akhigbe, A., \& Omuemu, V. (2009). Knowledge, attitudes and practice of breast cancer screening among female health workers in a Nigerian urban city. BMC Cancer, 9, 203. https://doi.org/10.1186/1471-2407-9-203

[39]. Ahmed, F., Mahmud, S., Hatcher, J., \& Khan, S. (2006). Breast cancer risk factor knowledge among nurses in teaching hospitals of Karachi, Pakistan: A cross-sectional study. BMC Nursing, 5, 6. https://doi.org/10.1186/1472-6955-5-6

[40]. Seah, M., \& Tan, S.M. (2007). Am I breast cancer smart? Assessing breast cancer knowledge among healthcare professionals. Singapore Medical Journal, 48(2), 58-162.

[41]. Altay, B., Avci1, I., Rizalar, S., Oz, H., \& Meral, D. (2015). Breast and cervical cancer knowledge and awareness among University students. Asian Pac $J$ Cancer Prev, 16(5), 1719-1724. https://doi.org/10.7314/APJCP.2015.16.5.1719

[42]. Ndukwe, E., Williams, K., \& Sheppard, V. (2013). Knowledge and perspectives of breast and cervical cancer screening among female African immigrants in the Washington D.C. metropolitan area. $J$ Cancer Educ, 28(4), 748-754. https://doi.org/10.1007/s13187-013-0521-x

[43]. Mohamed, A., Hassan, H., Gamel, W., \& Arafa, A. (2019). Awareness about breast and cervical cancers among nursing students in Beni-Suef University. Journal of Nursing Education and Practice, 9(5).

[44].Poonam, R., Nagaraj, K., \& Nirgude, A. (2012). Awareness of cervical cancer and effectiveness of educational intervention programme among nursing students in a rural area of Andhra Pradesh. Healthline, 3, 41-45.

[45]. Pandey, D., Vanya, V., Bhagat, S., Vs, B., \& Shetty, J. (2012). Awareness and attitude towards human papillomavirus (HPV) vaccine among medical students in a premier medical school in India. PLoS One, 7, 40619. https://doi.org/10.1371/journal.pone.0040619

[46].Joy, T., Sathian, B., Bhattarai, C., \& Chacko, J. (2011). Awareness of cervix cancer risk factors in educated youth: a cross-sectional, questionnaire-based survey in India, Nepal, and Sri Lanka. Asian Pac J Cancer Prev, 12, 1707-1712.

[47]. Pham, C., \& McPhee, S. (1992). Knowledge, attitudes, and practices of breast and cervical cancer screening among Vietnamese women. J Cancer Educ., 7(4), 305-310. https://doi.org/10.1080/08858199209528187

[48].Rezaeian, M., Sharifirad, G., Mostafavi, F., Moodi, M., \& Abbasi, M.H. (2014). The effects of breast cancer educational intervention on knowledge and health beliefs of women 40 years and older, Isfahan, Iran. Journal of Education and Health Promotion, 3, 43.

[49]. Gandeh, M., \& Milaat, W. (2000). Effect of a breast cancer health education program on the awareness and practice of Jeddah female secondary school students. Journal of Family \& Community Medicine, 7(1), 31-36.

[50]. Özerdoğan, N., Şahin, B., Kösgeroğlu, N., Culha, I., Çelik, N., Sayıner, F., et al. (2017). Educational study to increase breast cancer knowledge level and scanning participation among women working at a university. European Journal of Breast Health, 13(3), 113-116. https://doi.org/10.5152/ejbh.2017.3457

[51]. Akhtari-Zavare, M., Juni, M., Said, S., Ismail, I., Latiff, L., \& Eshkoor, S. (2016). Result of randomized control trial to increase breast health awareness among young females in Malaysia. BMC Public Health, 16, 738. https://doi.org/10.1186/s12889-016-3414-1

[52].Dignan, M., Sharp, P., Blinson, K., Michielutte, R., Konen, J., Bell, R., et al. (1995). Development of a cervical cancer education program for native American women in North Carolina. J Cancer Educ., 9(4), 235-242.

\section{Copyrights}

Copyright for this article is retained by the author(s), with first publication rights granted to the journal.

This is an open-access article distributed under the terms and conditions of the Creative Commons Attribution license (http://creativecommons.org/licenses/by/4.0/). 